\title{
AWARENESS REGARDING USE OF LINING UNDER POSTERIOR COMPOSITE RESTORATIONS AMONG GENERAL DENTISTS OF LAHORE
}

\author{
Salman Ashraf Khan, Obaid Bajwa, Naima Khalid, Nissa Khan \\ University College of Dentistry, University of Lahore, Lahore Pakistan
}

\begin{abstract}
Objective: To evaluate awareness among the General Dentists of Lahore regarding the use of lining materials under posterior resin restorations.

Study Design: Cross-sectional study.

Place and Duration of Study: The study was conducted in Lahore, from Sep 2019 to Jan 2020.

Methodology: Non-probability consecutive sampling technique was used. A sample size of 271 was calculated. The questionnaires were distributed by 2 surveyors to the general dentists of Lahore, Pakistan.

Results: The response rate was 100\%. Amongst these dentists, 191 (63.87\%) affirmed that they use lining materials in initial depth cavities, 248 (82.94\%) used lining material under moderate depth restorations and 285 (95.31\%) used lining materials under advanced depth cavities with calcium hydroxide being the most commonly used material.

Conclusion: The findings of the present study indicate that general dentists of Lahore are unaware of the contemporary concepts regarding the placement of cavity liners and tend to place liners in initial and moderate depth cavities under posterior resin restorations.
\end{abstract}

Keywords: Cavity linings, Dental, Permanent dental restoration, Resin composite.

This is an Open Access article distributed under the terms of the Creative Commons Attribution License (https://creativecommons.org/licenses/by-nc/4.0/), which permits unrestricted use, distribution, and reproduction in any medium, provided the original work is properly cited.

\section{INTRODUCTION}

Dental Amalgam has been used for $>150$ years as the primary choice for direct posterior restorations ${ }^{1}$.

Amalgam is an alloy of silver and tin mixed with liquid mercury. Its relatively lower cost, less technique sensitivity, high compressive strength, and good wear resistance contribute to its success and widespread use. The evidence suggests that amalgam restorations have the track record of being one of the longest lasting direct restorations intraorally ${ }^{2}$.

Having said this, one of the major safety concerns in the use of amalgam was presence mercury and proponents of composite resin used it to discourage amalgam use since $1970 \mathrm{~s}^{3}$. A lot of evidence was and is being published in support of amalgam safety. There is no evidence that suggests systemic toxic effects of amalgam on human health ${ }^{4}$. On the other hand, a report published by the UN in 2010 stated that almost 270-348 tons of mercury is used in dental procedures globally 70-100 tons of which enters the solid waste stream ${ }^{5}$. The Minamata Convention held in October 2013 on Mercury is a global treaty, signed by Pakistan and over one hundred countries with the intention of protecting human health and the environment from the adverse effects of mercury 6 .

The strategic measures advised for this transitio-

Correspondence: Dr Obaid Bajwa, Department of Operative Dentistry, University College of Dentistry, University of Lahore, Lahore Pakistan Received: 11 May 2020; revised received: 01 Oct 2020; accepted: 06 Oct 2020 nal phase out of amalgam included changing dentist's and patient's knowledge along with encouraging the use of amalgam alternatives. The dental amalgam use declined worldwide after the phase out timeline was put up by the Minamata Convention?.

Resin restorations became common and replaced amalgam as the choice of material for posterior teeth ${ }^{8}$. The resin based adhesive restorations required a modified tooth preparation strategy as opposed to conventional preparation for amalgam. Despite recent advances, composite resin restorations show less longevity and higher secondary caries as compared to amalgam restorations ${ }^{9}$.

Several proposed uses of a lining material include the reduction of bacteria, induction of reparative dentine, protection of pulp from thermal or chemical irritants and from restoration leakage. Although dental amalgam and composite resins are two entirely opposite entities in terms of material properties and behavior, the traditional lining strategies are still being practiced under composite resin restorations ${ }^{10}$. This study aims to evaluate awareness amongst the General Dentists of Lahore regarding the use of lining materials under direct posterior composite restorations.

\section{METHODOLOGY}

Approval for this study was taken from the Ethics and Research Committee of the University College of Dentistry (ref: UCD/ERCA/19/05). This cross-sectional study was conducted in Lahore, from 
September 2019 to January 2020. A structured questionnaire was designed which was partly adapted from another similar study conducted by Blum ${ }^{11}$. The questionnaire comprised of three sections, the first one consisting of questions regarding demographics. The second part inquired about their practices related to use, frequency and protocols followed for composite restorations. The last part was pertaining to the specific use of lining materials and the factors governing their use.

Inclusion criteria for the participants were certified PMDC Dentist who were also currently practicing General Dentistry.

The dentists who were excluded from the study were house officers, dentists who were not practicing and those who were not willing to participate.

The subjects were asked to respond to each item according to the response format provided in the questionnaire. No identifiable data like name or email address was obtained from the participants to keep their confidentiality. The consent was taken from the participants in the questionnaire in written form.

Sample size was calculated using Openepi calculator online. Sample size was of 271 with $90 \%$ confidence interval, $5 \%$ margin of error and $51 \%$ population of general dentists not using liners ${ }^{11}$. Using non-probability consecutive sampling technique, the questionnaires were hand distributed by 2 surveyors to the general dentists of Lahore. To achieve the required sample size, $13 \%$ extra questionnaires were circulated amongst the participants. Unexpectedly, 313 (100\%) replies were received which were scrutinized for data cleaning. After data scrutiny, 299 duly filled questionnaires were obtained and used for data analysis.

The data was compiled and analyzed using SPSS25. As descriptive statistics, frequencies and percentages were calculated. As inferential statistics, Pearson chi-square test was used to compare the scores of the samples with year of practice of general dentists. The $p$-value $\leq 0.05$ was considered statistically significant.

\section{RESULTS}

Among 299 participants, 63 (21.1\%) were females and $236(78.9 \%)$ were males. The percentages of graduate BDS general dentists were 209 (69.9\%), postgraduate trainees were $72(24 \%)$ and specialists were 18 (6.1\%).

Of the respondents, 151 (50.5\%) of subjects affirmed that they had completed their Bachelors in Dental Surgery in the past five years. One hundred and ten $(36.7 \%)$ completed their BDS within the past $5-10$ years and $39(12.8 \%)$ completed their graduation $>10$ years ago.

The participants were asked about the use of composite as a restorative material. Among those dentists, $299(100 \%)$ mentioned they used composite as a restorative material for posterior restorations and amongst these dentists.

Two hundred and ninety two (97.6\%) chose the option for using lining materials under the composite restorations. One hundred and twenty two (40.9\%) of the total dentists said that they placed $>20$ composite restorations in a month under posterior composite restorations. One hundred and sixteen (38.7\%) described that 21-40 restorations are being placed by them using composite under posterior composite restorations, $55(18.4 \%)$ placed 41-60 restorations in a month and 6 $(1.9 \%)$ placed $>60$ restorations in a month.

The respondents were asked a series of questions to ascertain their confidence in lining under different depths of preparations. One hundred and ten (36.8\%) of the participants chose not to place liners under initial depth restorations whereas 88 (29.4\%) chose to place calcium hydroxide as a lining material. Fifty three $(17.7 \%)$ opted not to place a lining material under moderate depth cavities whereas the most chosen lining material was calcium hydroxide opted by 110 (36.8\%) followed by RMGIC by 77 (25.8\%) dentists. Fourteen $(4.7 \%)$ of the dentists affirmed that they do not place lining under advanced depth cavities whereas the most commonly placed lining material was still calcium hydroxide (fig-1).

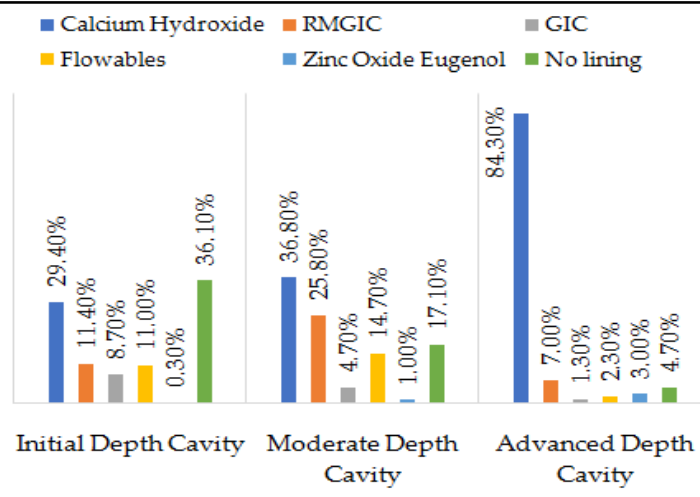

Figure-1: Use of lining materials under different depths of cavities.

The results of pearson chi-square test revealed significant difference between year of practice and usage of liner in preparation of initial depth cavity in restorative treatment $\left(X^{2}=31.262, p<0.001\right)$. The highest usage i.e. $104(34.7 \%)$ out of 154 (51.5\%) of liners 
was found in group 1 (having $\leq 5$ years of practice). Whereas The lowest usage of liners i.e. $15(5 \%)$ out of $37(12.4 \%)$ was found in group 3 (having >10 years of practice). This difference showed that with the increase of clinical experience, the usage of liners for initial depth cavity preparation decreases (table-I).

The results of Pearson chi-square test revealed significant difference between year of practice and usage of liner in preparation of moderate depth cavity in restorative treatment $\left(X^{2}=36.063, p<0.001\right)$. The highest usage i.e. $136(45.5 \%)$ of liners was found in group 1 (having $\leq 5$ years of practice). Whereas the lowest usage of liners i.e. Twenty three $(7.7 \%)$ out of $37(12.4 \%)$ was found in group 3 (having $>10$ years of practice) (table-II). used lining material under advanced depth cavities with the majority choosing calcium hydroxide as the first choice of material in this situation (table-III).

The dentists were also asked about the factors that influenced their choice of lining materials. They were allowed to select multiple options and the following results were obtained. Majority of the dentists (220) chose personal experience as one of the leading factors when selecting a lining material. The second most chosen option was availability (216 dentists) Other options that were chosen by more than half of the dentists were cost and recent evidence (fig-2).

The final question asked to the dentists was the frequency of post-operative sensitivity after placement of the lining materials and $107(35.8 \%)$ said they did

Table-I: Relationship between use of lining under initial depth cavities with years of experience of dentists.

\begin{tabular}{l|l|c|c|c|c|c|c}
\hline \multicolumn{2}{c|}{} & \multicolumn{5}{|c}{ Initial Depth Cavity Preparation } \\
\cline { 3 - 8 } \multicolumn{2}{c|}{} & $\begin{array}{c}\text { Calcium } \\
\text { Hydroxide }\end{array}$ & $\begin{array}{c}\text { Resin Modified } \\
\text { Glass Ionomer } \\
\text { Cement }\end{array}$ & $\begin{array}{c}\text { Glass } \\
\text { Ionomer } \\
\text { Cement }\end{array}$ & $\begin{array}{c}\text { Flow- } \\
\text { ables }\end{array}$ & $\begin{array}{c}\text { Zinc } \\
\text { Oxide }\end{array}$ & $\begin{array}{c}\text { No } \\
\text { Lining }\end{array}$ \\
\hline \multirow{2}{*}{$\begin{array}{c}\text { Year of } \\
\text { Practice }\end{array}$} & Within 5 years (group 1) & $21.1 \%$ & $4.7 \%$ & $4.3 \%$ & $5.0 \%$ & $0.3 \%$ & $16.1 \%$ \\
\cline { 2 - 9 } & $5-10$ years (group 2) & $6.7 \%$ & $5.4 \%$ & $4.0 \%$ & $7.4 \%$ & - & $12.7 \%$ \\
\hline
\end{tabular}

$\mathrm{X}^{2}=31.262, p<0.001$

Table-II: Relationship between use of lining under moderate depth cavities with years of experience of dentists.

\begin{tabular}{l|l|c|c|c|c|c|c}
\hline \multicolumn{2}{c|}{} & \multicolumn{5}{c}{ Moderate Depth Cavity Preparation } \\
\cline { 3 - 8 } \multicolumn{2}{c|}{} & $\begin{array}{c}\text { Calcium } \\
\text { hydroxide }\end{array}$ & $\begin{array}{c}\text { Resin Modified } \\
\text { Glass Ionomer } \\
\text { Cement }\end{array}$ & $\begin{array}{c}\text { Glass } \\
\text { Ionomer } \\
\text { Cement }\end{array}$ & $\begin{array}{c}\text { Flow- } \\
\text { ables }\end{array}$ & $\begin{array}{c}\text { Zinc } \\
\text { Oxide }\end{array}$ & $\begin{array}{c}\text { No } \\
\text { Lining }\end{array}$ \\
\hline \multirow{2}{*}{$\begin{array}{c}\text { Year of } \\
\text { Practice }\end{array}$} & Within 5 years (group 1) & $25.4 \%$ & $11.4 \%$ & $1.7 \%$ & $6.0 \%$ & $1.0 \%$ & $6.0 \%$ \\
\cline { 2 - 8 } & $5-10$ years (group 2) & $9.4 \%$ & $11.4 \%$ & $2.7 \%$ & $6.4 \%$ & - & $6.4 \%$ \\
\cline { 2 - 9 } & $>10$ years (group 3) & $2.0 \%$ & $3.0 \%$ & $0.3 \%$ & $2.3 \%$ & - & $4.7 \%$ \\
\hline
\end{tabular}

$\mathrm{X}^{2}=36.063, p<0.001$

Table-III: Relationship between the use of lining under advanced depth cavities with years of experience of dentists.

\begin{tabular}{l|l|c|c|c|c|c|c}
\hline \multicolumn{2}{c|}{} & \multicolumn{5}{c}{ Advanced depth cavity preparation } \\
\cline { 3 - 8 } \multicolumn{2}{c|}{} & $\begin{array}{c}\text { Calcium } \\
\text { hydroxide }\end{array}$ & $\begin{array}{c}\text { Resin Modified } \\
\text { Glass Ionomer } \\
\text { Cement }\end{array}$ & $\begin{array}{c}\text { Glass } \\
\text { Ionomer } \\
\text { Cement }\end{array}$ & $\begin{array}{c}\text { Flow- } \\
\text { ables }\end{array}$ & $\begin{array}{c}\text { Zinc } \\
\text { oxide }\end{array}$ & $\begin{array}{c}\text { No } \\
\text { lining }\end{array}$ \\
\hline \multirow{2}{*}{$\begin{array}{c}\text { Year of } \\
\text { Practice }\end{array}$} & Within 5 years (group 1) & $41.8 \%$ & $4.0 \%$ & $1.0 \%$ & $1.7 \%$ & - & $3.0 \%$ \\
\cline { 2 - 8 } & $5-10$ years (group 2) & $30.8 \%$ & $2.7 \%$ & $0.3 \%$ & $0.7 \%$ & $0.3 \%$ & $1.3 \%$ \\
\cline { 2 - 8 } & $>10$ years (group 3) & $11.6 \%$ & $0.4 \%$ & - & - & - & $0.4 \%$ \\
\hline
\end{tabular}

$\mathrm{X}^{2}=7.110, p=0.005$

The results of pearson chi-square test revealed significant difference between year of practice and usage of liner in preparation of moderate depth cavity in restorative treatment $\left(X^{2}=7.110, p=0.005\right)$. The use of liner in advanced depth cavities was very high in all the groups. One hundred and forty five (48.5\%) of the dentists with up to 5 years of experience, 104 $(34.7 \%)$ dentists with 5-10 years of experience and 34 $(11.6 \%)$ of the dentists with $>10$ years of experience not observe postoperative sensitivity after placement of a lining material whereas $192(64.2 \%)$ affirmed that they encountered postoperative hypersensitivity even after placement of a liner.

\section{DISCUSSION}

The use of liners and bases is traditionally associated with amalgam, mainly because these materials are necessary to provide thermal insulation between amalgam and underlying vital dentine ${ }^{12}$. 
Operative Dentistry textbooks provide us with guidelines for placement of liners under posterior restorations. Sturdevant's Art and Science of Operative Dentistry (7th Ed, 2019) recommends placement of a Resin Modified Glass Ionomer Cement (RMGIC) as a liner material when remain dentine thickness is 0.5-1.5 $\mathrm{mm}$, whereas placement of calcium hydroxide when the remaining dentine thickness is up to $0.5 \mathrm{~mm}$ followed by a base of RMGIC13. Picard's Manual of Operative Dentistry $\left(9^{\text {th }}\right.$ ed, 2011) recommends not using liners under initial and moderate depth cavities and using calcium hydroxide only in cases where direct pulp capping is needed ${ }^{14}$.

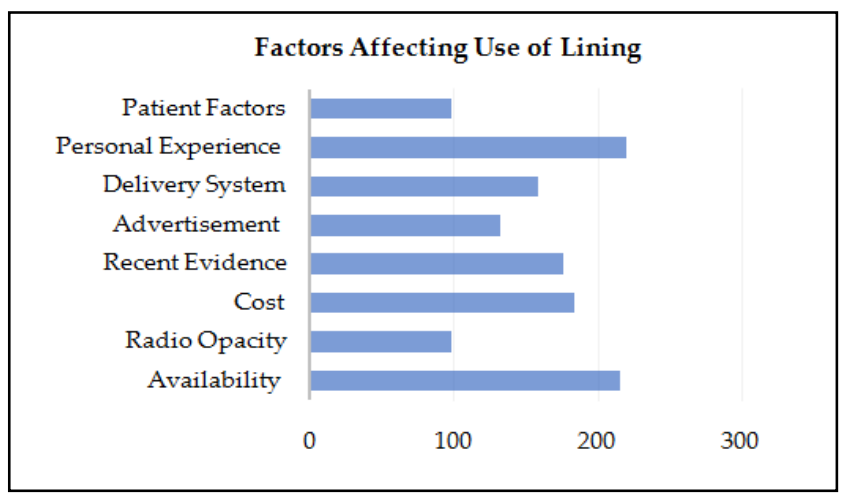

Figure-2: Factors affecting the use of liners amongst dentists.

In our study, majority of the dentists $(63.9 \%)$ were placing a liner even under initial depth tooth preparations. A similar study conducted in the UK showed that only $19 \%$ of the dentists there used lining under initial depth restorations ${ }^{11}$.

Calcium Hydroxide, GIC and flowables were most commonly used as lining materials in the study conducted by Igor and colleagues whereas Calcium Hydroxide was most commonly selected as the material of choice in our study followed by RMGIC.

There are a number of factors that contribute to the choice of lining materials. In the study conducted by Blum and colleagues the most important factors for choosing a lining material were availability, radioopacity and delivery system whereas in the present study availability and personal experience were the most commonly chosen factors ${ }^{11}$. Recent evidence, when not considered, may lead to following of older norms that may not be viable in the contemporary practices.

One of the major uses of lining materials is the cessation of post-operative sensitivity in the tooth being restored. It is a surprising finding that many of the participants in our study affirmed that post-operative sensitivity was an issue that they faced even after placement of the lining materials. This sensitivity can be attributed to many factors ${ }^{15}$.

The use of lining under resin restorations has been a subject of debate. Recent studies conclude that placing a liner under posterior resin-based restorations is an unnecessary step ${ }^{16}$. Other studies on anti-bacterial effects of the liners were not sufficiently supported by evidence ${ }^{17}$. Calcium Hydroxide can be washed out from under any restoration lacking proper marginal seal. Similar evidence shows that placement of liners has no beneficial effect on post-operative sensitivity ${ }^{15}$. Adherence of calcium hydroxide with dentinal floor is not complete hence it might cause formation of microgaps under the shrinkage stress and lead to secondary caries $^{18}$. Recent evidence does not support the placement of lining under posterior composites, except in situations in which the lining is intended to have therapeutic pulpal effects in deep preparations. Placement of a lining may affect the restored tooth's biomechanical properties adversely, limits the available surface area for bonding and reduces the thickness of resin composite. Sande and colleagues ${ }^{19}$ concluded that the presence of a lining neither extend nor reduce the survival of resin-based composite restorations. Furthermore, the application of a dentine bonding agent will seal the restoration and the underlying dentine protecting the pulp from stimuli and bacterial ingress. Therefore, there is no longer an indication to place a lining under a posterior resin composite restoration ${ }^{16}$.

There is a paradigm shift in the use of composite resin in posterior restorations led by Minamata Convention. The dental practitioners need to keep themselves abreast with the recent evidence to provide lasting restorations. More Continuing Professional Development (CPD) opportunities should be available to learn contemporary norms and a minimal hour requirement should be a prerequisite for the retention of practicing license by the regulatory authority.

\section{CONCLUSION}

The findings of the present study conclude that general dentists of Lahore are lacking awareness and are found to be uncertain regarding the use of lining materials under posterior composite restorations. This probably is because practitioners do not refer to recent evidence. Existing evidence suggests that a lining under a posterior resin composite may be indicated only in situations where it is intended to have therapeutic pulpal effects in deep cavities. 


\section{CONFLICT OF INTEREST}

This study has no conflict of interest to be declared by any author.

\section{REFERENCES}

1. Kingston G. The rise and fall of mercury amalgam. Prim Dent J 2013; 2(3): 745.

2. Alhareky M, Tavares M. Amalgam vs composite restoration, survival, and secondary caries. J Evid Based Dent Prac 2016; 16(2): 107-09.

3. Larsson KS. The dissemination of false data through inadequate citation. J Intern Med 1995; 238(5): 445-50.

4. Ajiboye A, Mossey P, Committee ISI, Fox C. International association for dental research policy and position statements on the safety of dental amalgam. J Dent Res 2020; 99(7): 763-68.

5. Fisher J, Varenne B, Narvaez D, Vickers C. The minamata convention and the phase down of dental amalgam. Bull World Health Organ 2018; 96(6): 436.

6. Mackey TK, Contreras JT, Liang BA. The minamata convention on mercury: attempting to address the global controversy of dental amalgam use and mercury waste disposal. Sci Total Environ 2014; 15(472): 125-29.

7. Alexander G, Hopcraft M, Tyas M, Wong R. Dentists' restorative decision-making and implications for an 'amalgamless' profession. Part 3: Dentists' attitudes. Aust Dent J 2016; 61(4): 502-13.

8. Lynch CD, McConnell RJ, Wilson N. Posterior composites: the future for restoring posterior teeth? Prim Dent J 2014; 3(2): 49.

9. Alcaraz MGR, Veitz-Keenan A, Sahrmann P, Schmidlin PR, Davis D, Iheozor-Ejiofor $Z$. Direct composite resin fillings versus amalgam fillings for permanent or adult posterior teeth. Cochrane Database Sys Rev 2014; 3: CD005620.
10. Kanzow P, Büttcher AF, Wilson NH, Lynch CD, Blum IR. Contemporary teaching of posterior composites at dental schools in Austria, Germany, and Switzerland. J Dent 2020; 96: 103321.

11. Blum IR, Younis N. Use of lining materials under posterior resin composite restorations in the UK. J Dent 2017; 57: 66-72.

12. Nasser M. Evidence summary: which dental liners under amalgam restorations are more effective in reducing postoperative sensitivity? Br Dent J 2011; 210(11): 533-37.

13. Ritter AV, Boushell LW, Walter R, Sturdevant CM. Sturdevant's art and science of operative dentistry. St. Louis, Missouri: Elsevier, \& 7th ed 2019. [Internet] Available from: https:// www.worldcat.org/title/sturdevants-art-and-science-ofoperative-dentistry/oclc/1022775520

14. Banerjee A, Watson TF. Pickard's manual of operative dentistry. 9th ed. 2011 [Internet] Available from: https://www.academia. edu/36609722/Pickards_Manual_of_Operative_Dentistry_9th_e dition_pdf.

15. Sabbagh J, Fahd JC, McConnell RJ. Post-operative sensitivity and posterior composite resin restorations: a review. Dent Update 2018; 45(3): 207-13.

16. Schenkel AB, Peltz I, Veitz-Keenan A. Dental cavity liners for class I and class II resin-based composite restorations. Cochrane Database Syst Rev 2016; 2016(10): 1-38.

17. Schwendicke F, Tu YK, Hsu LY, Goestemeyer G. Antibacterial effects of cavity lining: asystematic review and network metaanalysis. J Dent 2015; 43(11): 1298-307.

18. von Fraunhofer J, Marshall K, Holman B. The effect of base/liner use on restoration leakage. Gen Dent 2006; 54(2): 106.

19. van de Sande FH, Rodolpho PADR, Basso GR, Patias R, da Rosa $\mathrm{QF}$, Demarco FF, et al. 18-year survival of posterior composite resin restorations with and without glass ionomer cement as base. Dent Mater 2015; 31(6): 669-75. 